\title{
Epidemiological Survey of Toxoplasma gondii and Associated Risk Factors in Ruminant Species of the Khyber Pakhtunkhwa Province of Pakistan
}

\author{
Abid Ali $\mathbb{D}^{1,2}$ Talha Omer, ${ }^{3}$ Asad Ullah, ${ }^{4}$ Abdul Haleem, ${ }^{5}$ Maryam Naseem, ${ }^{6}$ Mujeeb Ullah, \\ Seemab, ${ }^{5}$ Fahad Shamim, ${ }^{5}$ Amna Tehreem, ${ }^{7}$ Muhammad Bilal, ${ }^{8}$ \\ and Muhammad Numan Khan $\mathbb{D}^{9}$ \\ ${ }^{1}$ Department of Zoology, Government Degree College Akbarpura Nowshera, Pakistan \\ ${ }^{2}$ Genomic Laboratory, Veterinary Research Institute, Livestock Department Peshawar KP, Pakistan \\ ${ }^{3}$ Department of Statistics and Computer Science University of Veterinary and Animal Sciences Lahore, Pakistan \\ ${ }^{4}$ Department of Zoology, University of Agriculture Faisalabad, Pakistan \\ ${ }^{5}$ Department of Zoology, Islamia College Peshawar, Pakistan \\ ${ }^{6}$ Department of Zoology, University of Peshawar, Pakistan \\ ${ }^{7}$ Department of Zoology, Government College Women University Faisalabad, Pakistan \\ ${ }^{8}$ Department of Fisheries and Aquaculture, University of Veterinary and Animal Sciences, Lahore, Pakistan \\ ${ }^{9}$ Department of Zoology, Quaid e Azam University Islamabad, Pakistan \\ Correspondence should be addressed to Abid Ali; abid.biosci@gmail.com \\ and Muhammad Numan Khan; muhmmadnomankhan1@gmail.com
}

Received 19 October 2020; Revised 20 December 2020; Accepted 19 January 2021; Published 3 February 2021

Academic Editor: Eric Agola Lelo

Copyright ( $\odot 2021$ Abid Ali et al. This is an open access article distributed under the Creative Commons Attribution License, which permits unrestricted use, distribution, and reproduction in any medium, provided the original work is properly cited.

Toxoplasma infection is one of the most common human parasitic diseases. During 2018-2020, in the rural areas of three districts of Pakistan, we surveyed a total of 451 animals, belonging to different asymptomatic ruminant species, to determine the prevalence of Toxoplasma gondii antibodies. We used ELISA assay as well as recorded some associated risk factors contributing to its transmission. IgM antibodies were detected in $17 \%$ and IgG in $13.4 \%$ of ruminant samples with the highest percentage, $10 \%$ for IgM and $8.6 \%$ for IgG in sheep. A strong significant association was found between antibodies and different species (IgM, $\chi^{2}=29.280, P=.000$, and IgG, $\chi^{2}=22.580, P=.000$ ), respectively. Infection with $T$. gondii seems mainly associated with different geographic features and the presence of cats in the environment, low hygiene water systems and livestock that are mostly dependent on outdoor drinking and grazing. There was no significant association between IgM and age grouping $\left(\chi^{2}=6.660, P=0.840\right.$ nor for $\operatorname{IgG}\left(\chi^{2}=8.136, P=\right.$ 0.43). The results of this study may be considered the starting point to promote the awareness about parasitic infections in ruminants in Pakistan in order to prevent this infection from further spreading.

\section{Introduction}

Toxoplasma infection is a common human parasitic disease worldwide, and it is estimated that the prevalence in people is about 1-2 billion [1]. Toxoplasma infection is a cosmopolitan zoonotic disease caused by a coccidian protozoan, Toxoplasma gondii, which mostly affects humans, mammals, and birds [2]. T. gondii causes many severe diseases, for example, chorioretinitis, serious congenital pathologies like cerebral calcification, microcephaly, and seizer disorders. Most of the congenital infections are believed to have asymptomatic and spontaneous abortion or stillbirth [3], and in immunocompromised people, it is cause of myocarditis, pneumonitis, and encephalitis [4].

The ratio of toxoplasma infection is even common in developed countries. For example, in the USA, 400-4000 
infants are born with congenital toxoplasmosis annually and record complications like bipolar disorder, schizophrenia, and obsessive-compulsive disorder that are linked to T. gondii [5]. Different regions of the world have different frequencies of infection because of differences in culture, eating systems, and the types of management of livestock [6,7]. Countries where food is thoroughly cooked have less seroprevalence (10-40\%) [8].

Sheep and goats, and other small ruminants, are mostly infected by T. gondii as compared to cattle and buffalo due to a comparatively weak immune system [9]. Toxoplasma infection is also a public health issue owing to its transmission to humans by ingestion of undercooked meat containing tissue cysts, or by consuming food or drink contaminated with oocysts, or through accidental ingestion of sporulated oocysts from the environment [10-12].

The definitive hosts of this parasite are domestic cats and various other species of wild felids, while the intermediate hosts are mammals and birds [13]. Mammal meat with infected T. gondii is the most common source of infection for humans [14] Meat from small ruminants have a high chance of infection especially in those countries where the consumption of sheep and goat meat is part of the culinary tradition [15-17]. Milk from infected animals is another infection route [18].

In rural areas of Pakistan, children with allergies to cow/buffalo milk are consuming small ruminant milk, such as goat. The prevalence of $T$. gondii in human population of Pakistan ranges from 12 to $28 \%[19,20]$. T. gondii rates are higher in pregnant women, 63\% from Punjab, 38\% from Khyber Pakhtunkhwa Province, and $48 \%$ prevalence from Azas Jammu and Kashmir [21].

Toxoplasmosis causes great economic losses in ruminants, especially in sheep, cattle, and goats by causing early embryonic death, fetal, neonatal death, abortion, stillbirth, death, and reduced flock milk production [22-24]. In the Charsada district of Pakistan, T. gondii is present in $17.3 \%$ of buffalo and up to $40 \%$ of sheep, as determined using a latex agglutination test [25]. T. gondii was recorded in sheep with $44.13 \%$ and $42.28 \%$ in goats in the district of Mardan using indirect hemagglutination antibody (IHA) test [26]. Different serological tests recorded about $41 \%$ seropositivity of T. gondii in sheep in the Khyber Pakhtunkhwa Province [27]. Despite the high influence of the parasite in animal and human health, the epidemiological information about toxoplasma infection is scarce in Pakistan. Therefore, the knowledge about the seroprevalence of $T$. gondii in ruminants is of interest in order to implement future strategies on public health programs and to clarify the role of livestock as a source of infection in three main districts of Khyber Pakhtunkhwa province of Pakistan.

\section{Materials and Methods}

2.1. Study Area. Three districts were selected for the study including Peshawar, Mardan, and Charsadda of Khyber Pakhtunkhwa province, Pakistan (Figure 1). Peshawar is located from $33^{\circ}-44$ to $34^{\circ}-15$ North latitudes and $71^{\circ}-22$ to $71^{\circ}-42$ East longitudes, Mardan which is located from $34^{\circ}$ $05^{\prime}$ to $34^{\circ}-32$ north latitude and $71-48$ to $72^{\circ}-25$ East latitude having total of $1632 \mathrm{~km} 2$ area, and finally Charsadda which is located between 34-030 and 34-380 north latitudes and 71280 and 71-530 east longitudes. There is a temperate climate. In summer, the mean maximum temperature in Peshawar district exceeds $40^{\circ}$, while the mean minimum temperature is $25^{\circ} \mathrm{C}$. During winter, the maximum is $18.35^{\circ} \mathrm{C}$, while the mean minimum temperature is $4^{\circ} \mathrm{C}$. The average annual precipitation level is about 400 millimeters, while the highest annual rainfall recorded of 904.5 millimeters, and the relative humidity varies from $46 \%$ to $76 \%$ from June through August. In Mardan, the temperature reaches its maximum in the month of June, i.e., $41.5^{\circ} \mathrm{C}$. The mean minimum temperature in the month of January is $2.1^{\circ} \mathrm{C}$. In August, the maximum rainfall is $125.85 \mathrm{~mm}$. In December, the maximum humidity has recorded about $73.33 \%$. The tract is generally wet, moist, and humid and this could be due to irrigation and cultivation, whereas district Charsadda has an annual average rainfall of $16.5 \mathrm{~cm}$ [28].

2.2. Blood Specimens. The present study was carried out from 2018 to 2020 in the rural area of three districts, MardanCharsadda and Peshawar of Pakistan, where we surveyed a total of $n=451$ formers. Before sampling, we arranged a meeting with the local specialist officers for livestock in each district. Random blood samples were taken from ruminants in different. The majority of samples were from sheep (167), goat (126), cow (100), and buffalo (58) (Table 1). About $2 \mathrm{~mL}$ of blood was collected from the jugular vein through a sterile syringe from each ruminant. The serum was separated and stored at $-20^{\circ} \mathrm{C}$ until used. Sera were extracted from blood samples by centrifugation at $2000 \times \mathrm{g}$ for $10 \mathrm{~min}$.

2.3. Questionnaire Survey. Moreover, we also prepared a questionnaire in collaboration with local specialists. We surveyed all possible farmers from whom we collected samples. The questionnaire was available in Urdu, a national language of Pakistan. The purpose of the survey was to find the association of different risk factors with the T. gondii transmission in ruminant. Respondents were interviewed for questions such as type of species they have, location, hygienic status, cat in the vicinity, drinking water either indoor or outdoor, and were livestock free-living or caged. The following investigation received ethical approval by the farmers.

2.4. Enzyme-Linked Immunosorbent Assay. ELISA kits (BioELISA Toxo-IgM and IgG kits) were used for Ruminant Serum Toxoplasmosis and the detection of anti- $T$. gondii antibodies (purchased from Biokit, S.S. Barcelona Spain) and used according to the supplier's instructions.

2.5. Statistical Analysis. We first choose IgM as a dependent variable while keep gathered gender, age, location, and others as independent variables in order to evaluate if there is a significant association between these variables and possible antibodies for $T$. gondii in ruminant species. The same process was repeated for IgG antibody. Statistical analysis of frequencies was calculated using the chi-square test $\left(\chi^{2}\right)$. We also run a binary logistic regression while keeping the $\operatorname{IgM}$ and IgG antibodies as dependent variables separately to evaluate the possible risk factors such as hygienic system, water 


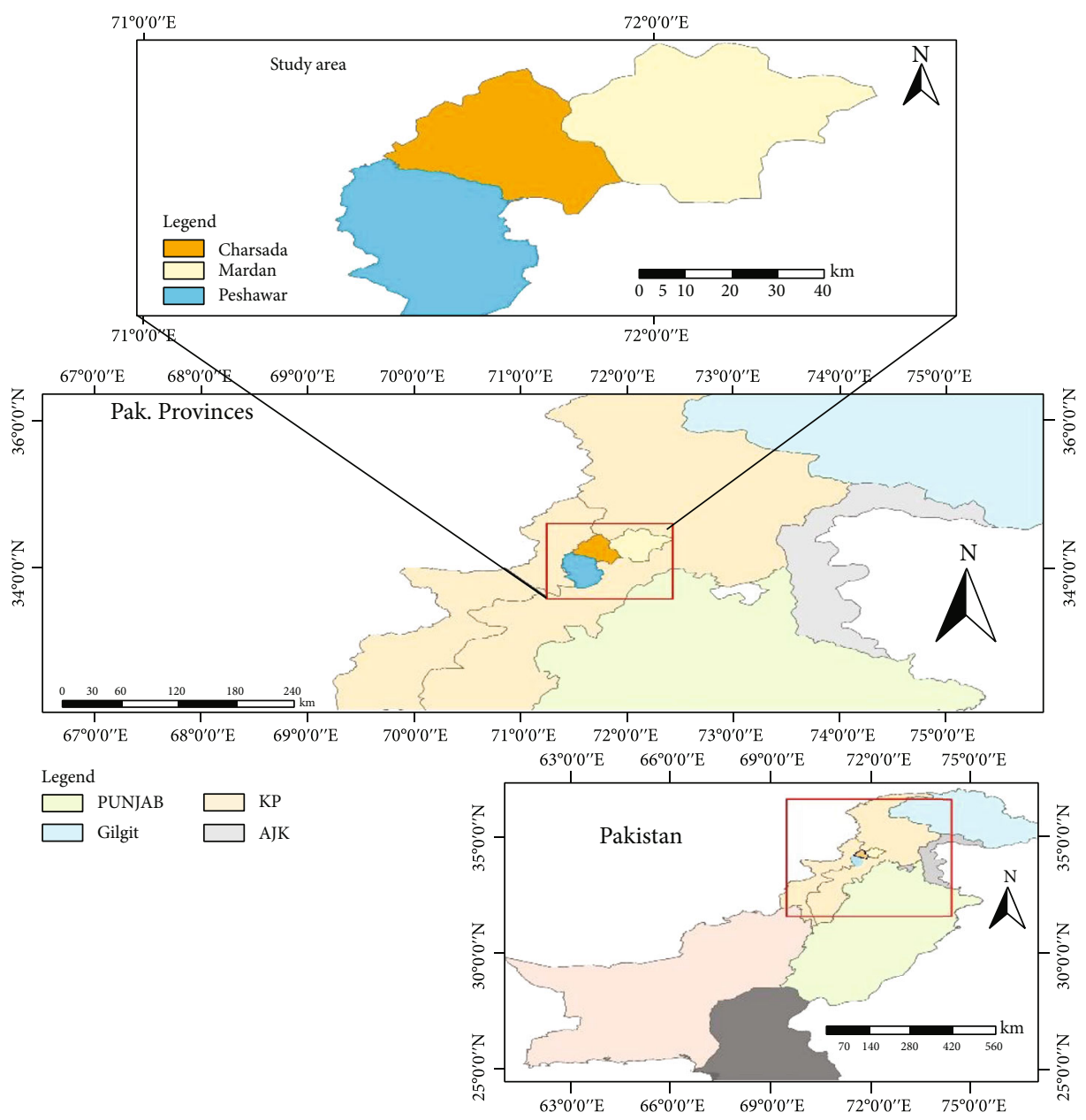

Figure 1: Different study areas in the Khyber Pakhtunkhwa Province of Pakistan.

TABle 1: Total number of sera examined along with antibody positivity from different species in the study area.

\begin{tabular}{lccc}
\hline Species & Total samples & IgM positive & IgG positive \\
\hline Sheep & 167 & 49 & 39 \\
Goat & 126 & 13 & 10 \\
Cow & 100 & 10 & 8 \\
Buffalo & 58 & 5 & 4 \\
Total & 451 & 77 & 61 \\
\hline
\end{tabular}

intake, cat in the vicinity, and living lifestyle. All the analyses were run through SPSS version 25 for windows, and the differences were considered statistically significant at $<0.05$.

\section{Results}

All samples were tested for T. gondii using ELISA commercial kits. There was some variation among both the antibodies in overall samples, for example, the IgM antibodies were found in $17.0 \%$ and $\operatorname{IgG}$ in $13.4 \%$ of the total collected samples. For that location, the seropositivity of T. gondii for IgM and IgG was $10.8 \%$ and $10.1 \%$ at Mardan and $3.7 \%$ and $2.2 \%$ at Peshawar, and only $2.4 \%$ and $1.1 \%$ was recorded at Charsadda district, respectively. Therefore, the places were remained significant for IgM and IgG antibodies $\left(\chi^{2}=\right.$ 101.181, $\left.P=.000, \chi^{2}=22.804, P=.000\right)$, respectively. Among all ruminants, the youngest age group, up to one year, was most infected (11\% for IgM and $9.5 \%$ for $\operatorname{IgG}$ ), and other age groups remained less infected for both antibodies. However, there was no significant association we recorded nether for $\operatorname{IgM}\left(\chi^{2}=6.660, P=0.840\right.$ nor for $\operatorname{IgG}\left(\chi^{2}=8.136, P=\right.$ 0.43 ) in different age groups, respectively.

For individual species, we recorded $10 \%$ of sheep with IgM positive antibodies and $8.6 \%$ for IgG. Similarly, the antibodies in cow with the manner that the IgM was higher with $2.8 \%$ while only $2.2 \%$ of IgG were found. However, in goat, IgM was recorded lower with $2 \%$ and slightly higher IgG with $2.2 \%$ was noted. In buffalo, the IgM was again higher with $1.1 \%$ and lower IgG was recorded with $0.8 \%$. There was a strong significant association between different species and positivity for both $\operatorname{IgM}$ and $\operatorname{IgG}\left(\chi^{2}=29.280, P=.000\right.$, and $\left.\chi^{2}=22.580, P=.000\right)$, respectively. Tables 2 and 3 .

Moreover, binary logistic regression revealed that cats in the vicinity, water intake, and hygienic system were strongly associated with the transmission of $T$. gondii in ruminants. Association of these risk factors with different antibodies such as IgM and IgG is given in Tables 4 and 5 . 
TABLE 2: Possible risk factors associated with higher IgM antibody of Toxoplasma gondii prevalence in Ruminants using chi-square analysis.

\begin{tabular}{|c|c|c|c|c|c|}
\hline Variables & Categories & Total & IgM positive (\%) & Chi-square test value & $P$ value \\
\hline \multirow{2}{*}{ Gender } & Male & 190 & $34(17)$ & \multirow{2}{*}{.157} & \multirow{2}{*}{.692} \\
\hline & Female & 261 & $43(16.4)$ & & \\
\hline \multirow{3}{*}{ Age } & Up to one year & 242 & $51(21)$ & \multirow{3}{*}{6.660} & \multirow{3}{*}{0.84} \\
\hline & One to two years & 166 & $19(11.4)$ & & \\
\hline & Three years and above & 42 & $7(16)$ & & \\
\hline \multirow{3}{*}{ Location } & Peshawar & 135 & $17(12.5)$ & \multirow{3}{*}{101.181} & \multirow{3}{*}{0.006} \\
\hline & Mardan & 213 & $49(23)$ & & \\
\hline & Charsadda & 103 & $11(10.6)$ & & \\
\hline \multirow{4}{*}{ Species } & Cow & 100 & $13(13)$ & \multirow{4}{*}{29.280} & \multirow{4}{*}{.000} \\
\hline & Sheep & 167 & $49(29)$ & & \\
\hline & Goat & 126 & $10(7.9)$ & & \\
\hline & Buffalo & 58 & $5(8.6)$ & & \\
\hline \multirow{2}{*}{ Cat in the vicinity } & Yes & 240 & $54(22.5)$ & \multirow{2}{*}{10.671} & \multirow{2}{*}{.001} \\
\hline & No & 211 & $23(10.9)$ & & \\
\hline \multirow{3}{*}{ Hygienic system } & High & 74 & $6(8)$ & \multirow{3}{*}{13.644} & \multirow{3}{*}{.001} \\
\hline & Moderate & 179 & $23(12.8)$ & & \\
\hline & Low & 198 & $48(24)$ & & \\
\hline \multirow{2}{*}{ Living } & Free & 83 & $10(12)$ & \multirow{2}{*}{1.814} & \multirow{2}{*}{.178} \\
\hline & Caged & 368 & $67(18)$ & & \\
\hline \multirow{2}{*}{ Water intake } & Indoor & 312 & $38(12)$ & \multirow{2}{*}{17.446} & \multirow{2}{*}{.000} \\
\hline & Outdoor & 138 & $39(28)$ & & \\
\hline
\end{tabular}

TABLE 3: Possible risk factors associated with higher IgG antibodies of Toxoplasma gondii prevalence in ruminants using chi-square analysis.

\begin{tabular}{|c|c|c|c|c|c|}
\hline Variables & Categories & Total & IgG positive (\%) & Chi-square test value & $P$ value \\
\hline \multirow{2}{*}{ Gender } & Male & 190 & $26(15)$ & \multirow{2}{*}{.007} & \multirow{2}{*}{.933} \\
\hline & Female & 261 & $35(13.4)$ & & \\
\hline \multirow{3}{*}{ Age } & One to five months & 242 & $43(17.7)$ & \multirow{3}{*}{8.136} & \multirow{3}{*}{0.43} \\
\hline & Five to eighteen months & 166 & $14(8.4)$ & & \\
\hline & Eighteen and above & 42 & $4(9.5)$ & & \\
\hline \multirow{3}{*}{ Location } & Peshawar & 135 & $10(7.4)$ & \multirow{3}{*}{22.804} & \multirow{3}{*}{.000} \\
\hline & Mardan & 213 & $46(21.5)$ & & \\
\hline & Charsadda & 103 & $5(4.8)$ & & \\
\hline \multirow{4}{*}{ Species } & Cow & 100 & $10(10)$ & \multirow{4}{*}{22.580} & \multirow{4}{*}{.000} \\
\hline & Sheep & 167 & $39(23)$ & & \\
\hline & Goat & 126 & $8(6)$ & & \\
\hline & Buffalo & 58 & $4(6)$ & & \\
\hline \multirow{2}{*}{ Cat in the vicinity } & Yes & 240 & $48(20)$ & \multirow{2}{*}{18.386} & \multirow{2}{*}{.000} \\
\hline & No & 211 & $13(6)$ & & \\
\hline \multirow{3}{*}{ Hygienic system } & High & 74 & $3(4)$ & \multirow{3}{*}{11.958} & \multirow{3}{*}{.003} \\
\hline & Moderate & 179 & $20(11)$ & & \\
\hline & Low & 198 & 38 (19) & & \\
\hline \multirow{2}{*}{ Living } & Free & 83 & $10(12)$ & \multirow{2}{*}{.190} & \multirow{2}{*}{.663} \\
\hline & Caged & 368 & $51(13.8)$ & & \\
\hline \multirow{2}{*}{ Water intake } & Indoor & 312 & $27(8.6)$ & \multirow{2}{*}{20.861} & \multirow{2}{*}{.000} \\
\hline & Outdoor & 138 & $34(24.6)$ & & \\
\hline
\end{tabular}


TABLE 4: Associated possible risk factors with IgM antibody of Toxoplasma gondii prevalence in ruminants using binary logistic model.

\begin{tabular}{|c|c|c|c|c|c|c|c|c|}
\hline \multirow{2}{*}{ Variable } & \multirow{2}{*}{ B } & \multirow{2}{*}{ S.E. } & \multirow{2}{*}{ Wald } & \multirow{2}{*}{$\mathrm{df}$} & \multirow{2}{*}{ Sig. } & \multirow{2}{*}{$\operatorname{Exp}(B)$} & \multicolumn{2}{|c|}{ 95\% C.I. for EXP (B) } \\
\hline & & & & & & & Lower & Upper \\
\hline Hygienic system & -.716 & .201 & 12.641 & 1 & .000 & .489 & .329 & .725 \\
\hline Water intake & -1.006 & .266 & 14.311 & 1 & .000 & .366 & .217 & 616 \\
\hline Cat in the vicinity & .771 & .279 & 7.627 & 1 & .006 & 2.162 & 1.251 & 3.736 \\
\hline Living lifestyle & -.605 & .380 & 2.535 & 1 & .111 & .546 & .259 & 1.150 \\
\hline Constant & 4.711 & 1.084 & 18.879 & 1 & .000 & 111.214 & & \\
\hline
\end{tabular}

TABLE 5: Association of possible risk factors with IgG antibody of Toxoplasma gondii prevalence in ruminants using binary logistic model.

\begin{tabular}{lccccccc}
\hline Variable & B & S.E. & Wald & df & Sig. & Exp (B) & $\begin{array}{r}\text { 95\% C.I. for EXP (B) } \\
\text { Lower }\end{array}$ \\
\hline Hygienic system & -.752 & .230 & 10.733 & 1 & .001 & .471 & .301 \\
Water intake & -1.171 & .294 & 15.871 & 1 & .000 & .310 & .174 \\
Cat living in the vicinity & 1.258 & .338 & 13.845 & 1 & .000 & 3.517 & 1.813 \\
Living lifestyle & -.236 & .395 & .357 & 1 & .550 & .790 & .364 \\
Constant & 4.038 & 1.169 & 11.938 & 1 & .001 & 56.722 & 1.714 \\
\hline
\end{tabular}

\section{Discussion}

In order to evaluate the seroprevalence of T. gondii in ruminants, we investigated three districts of Pakistan. Infection caused by $T$. gondii is a serious threat to humans due to its complicated nature and transmission, while also has influence on economic growth as it is responsible for negative impacts on reproductive efficiency in farm ruminants worldwide $[29,30]$. Since observation of cyst directly from the tissue is difficult, we used serological techniques that appear to identify the presence of T. gondii [31].

The use of ELISA has been widely documented in epidemiological studies for the detection T. gondii antibodies in ruminants $[32,33]$. Our study found a seroprevalence for T. gondii of about $17 \%$ for IgM and $13.4 \%$ for IgG. The antibodies were not always aligned, and this could be due to the serum IgG and IgM immune assays that are used to differentiate chronic and acute infection and population surveillance of T. gondii [34]. It is pertinent that the specificity and sensitivity of different serological tests used to detect $T$. gondii antibodies in cattle sera has not been determined, because viable $T$. gondii has been rarely isolated [15].

Our study show contradiction with reports from Spain (41\%) [35], Serbia (76.3\% in cattle, and $84.5 \%$ in sheep) [36], Greece (39.72\%) [37], Italy (92\%) [38], and Brazil (71\%) in cattle [39], where there was a high proportion of ruminants exposed to the parasite. Nevertheless, the prevalence rate recorded in the current study was higher in respect to data from Lara State, Venezuela (6.3\%) for goats [40], China (4.4\%) for sheep [41], and India (3.2\%) for goats [42]. Thus, the present study is consistent with the idea that different cultures, foods, and geography are important factors regulating the spread of $T$. gondii in different regions [43]. Differences in prevalence rates between countries may also be due to different husbandry methods used in these regions
$[35,44]$. Further, it can be related to differences in techniques used in each study to monitor the T. gondii antibody [34]. Perhaps, the climate is another important factor contributing to this [45].

We also recorded that the antibodies of $T$. gondii were different in different species. For example, sheep was the most affected animal species by $T$. gondii from all three districts, and this corroborates with a study recently reported from Magnolia [46] with prevalence of $34.8 \%$ in sheep and $32 \%$ in goats, from Ghana [47] with $33.2 \%$ in sheep and $26.8 \%$ in goat, and from Greece [48] with $48.6 \%$ in sheep ad $30.7 \%$ in goat using ELISA. Thus, among different species, sheep is more likely to be infected. Nevertheless, our study show contrasts where T. gondii in sheep was $11.2 \%$ compared to $25.4 \%$ in goats and also of a low prevalence in adult sheep and goats [49]. Consequently, the result of our and other studies revealed that sheep and goats are the species most often infected with T. gondii; however, cattle and buffaloes are considered to have lower rates of infection given the fact large ruminants are more resistant to T. gondii $[9,50]$.

Environment, geography, presence of cats, the rearing system, and age all have vital as major risk factors in the distribution of $T$. gondii infection [7, 51, 52]. In this study, the high prevalence was observed from the District Mardan when compared to District Peshawar. The high right in District Mardan might be due to the high density of ruminants [53], and it may be due to cats in the vicinity [51]. Cat populations are definitive hosts of T. gondii, which may impact and control the spread of pathogens in the environment $[54,55]$, and a dry climate is another key fact that influences the sporulation of oocysts in the environment [56]. The current study found that all three different districts had different hygienic standards, drinking water type, and type of confinement, ecological conditions, and annual rainfall, changes in the habits of consumers $[57,58]$. 
As an animal ages, its cumulative likelihood for exposure increases. Given the fact, the age of animals plays an important role in the prevalence rate of $T$. gondii infection in animals $[26,49]$. Among both, the sheep and goats from the group up to one year were highly seropositive as compared to the 1-2 years age group. This could due to the age groups one year and less had not properly maternal passive immunity remaining. In the present study, no correlation was found among sex groups in ruminants, while there were in water drinking places such as we recorded higher infection in animal drinking water outdoor than indoor. Therefore, this could be considered a risk factor for ruminants while drinking outdoor.

\section{Conclusions}

The seropositivity of T. gondii was higher in sheep, and Mardan was found to be somewhat affected among the three districts. This is what environment and geography play an important role and are considered major risk factors in the distribution of $T$. gondii infection. This assumed that the given regions have some percentage of infection, however, lower from other parts of Pakistan. Therefore, there is advance screening performance that needs to investigate the disease continuously in order to prevent such a spreading in the regions. Also, there needs to be more education for farmers as well as proper screening at slaughterhouses which is essential for the prevention of T. gondii in humans.

\section{Data Availability}

The data supporting he findings of this study are available upon reasonable request from the corresponding author.

\section{Conflicts of Interest}

The authors declare no conflict of interest.

\section{Authors' Contributions}

All authors have equal contribution in the study.

\section{Acknowledgments}

We are very thankful to Professor Francesca Mancianti and Adrian Paterson for their suggestions and for reviewing the study. We are thankful to all those members of the Livestock department who encouraged the local community to compensate for this study.

\section{References}

[1] H. R. Chang, "The potential role of azithromycin in the treatment or prophylaxis of toxoplasmosis," International Journal of STD \& AIDS, vol. 7, no. 1, pp. 18-22, 1996.

[2] H. Ahmed, A. Malik, M. Arshad et al., "Seroprevalence and spatial distribution of toxoplasmosis in sheep and goats in North-Eastern Region of Pakistan," The Korean Journal of Parasitology, vol. 54, no. 4, pp. 439-446, 2016.
[3] P. Zhou, Z. Chen, H.-L. Li et al., "Toxoplasma gondii infection in humans in China," Parasites \& Vectors, vol. 4, pp. 1-9, 2011.

[4] L. M. Weiss and J. P. Dubey, "Toxoplasmosis: a history of clinical observations," International Journal for Parasitology, vol. 39, no. 8, pp. 895-901, 2009.

[5] A. I. Egorov, R. Converse, S. M. Griffin et al., "Environmental risk factors for Toxoplasma gondii infections and the impact of latent infections on allostatic load in residents of Central North Carolina," BMC Infectious Diseases, vol. 18, no. 1, p. 421, 2018.

[6] A. M. Tenter, A. R. Heckeroth, and L. M. Weiss, "ErratumToxoplasma gondii: From animals to humans (International Journal for Parasitology (2000) 30 (1217-1258) PII: S0020751900001247)," International Journal for Parasitology, vol. 31, pp. 217-220, 2001.

[7] A. Gazzonis, L. Villa, M. Manfredi, and S. J. A. Zanzani, "Spatial analysis of infections by Toxoplasma gondii and Neospora caninum (Protozoa: Apicomplexa) in small ruminants in Northern Italy," Animals, vol. 9, no. 11, p. 916, 2019.

[8] P. Zuber and P. Jacquier, "Epidemiologie de la toxoplasmose: situation au niveau mondial," Schweizerische Medizinische Wochenschrift, vol. 125, p. 19S, 1995.

[9] L. Ciuca, G. Borriello, A. Bosco et al., "Seroprevalence and clinical outcomes of Neospora caninum, Toxoplasma gondii and Besnoitia besnoiti infections in Water Buffaloes (Bubalus bubalis)," Animals, vol. 10, no. 3, p. 532, 2020.

[10] C. Alvarado-Esquivel, S. Estrada-Martínez, H. Pizarro-Villalobos, M. Arce-Quiñones, O. Liesenfeld, and J. P. Dubey, "Seroepidemiology of Toxoplasma gondii infection in general population in a northern Mexican city," Journal of Parasitology, vol. 97, no. 1, pp. 40-43, 2011.

[11] K. S. Pereira, R. M. Franco, and D. A. Leal, "Transmission of toxoplasmosis (Toxoplasma gondii) by foods," in Advances in food and nutrition research, pp. 1-19, Elsevier, 2010.

[12] O. Djurković-Djaković, J. Dupouy-Camet, J. van der Giessen, J. P. J. F. Dubey, and W. Parasitology, "Toxoplasmosis: overview from a one health perspective," Food and Waterborne Parasitology, vol. 15, article e00054, 2019.

[13] A. Nematollahi and G. Moghddam, "Survey on seroprevalence of anti-Toxoplasma gondii antibodies in cattle in Tabriz (Iran) by IFAT," American Journal of Animal and Veterinary Sciences, vol. 3, no. 1, pp. 40-42, 2008.

[14] M. Gharbi, L. Zribi, M. Jedidi et al., "Prevalence of Toxoplasma gondii infection in Tunisian sheep," Bulletin de la Societe de Pathologie Exotique, vol. 106, pp. 184-187, 2013.

[15] I. García-Bocanegra, O. Cabezón, E. Hernández, M. S. Martínez-Cruz, Á. Martínez-Moreno, and J. Martínez-Moreno, "Toxoplasma gondiiin ruminant species (cattle, sheep, and goats) from southern Spain," vol. 99, pp. 438-440, 2013.

[16] A. Kijlstra and E. Jongert, "Control of the risk of human toxoplasmosis transmitted by meat," International Journal for Parasitology, vol. 38, no. 12, pp. 1359-1370, 2008.

[17] J. L. Garcia, I. T. Navarro, O. Vidotto et al., "Toxoplasma gondii: comparison of a rhoptry-ELISA with IFAT and MAT for antibody detection in sera of experimentally infected pigs," vol. 113, pp. 100-105, 2006.

[18] S. Boughattas, "Toxoplasma infection and milk consumption: meta-analysis of assumptions and evidences," Critical Reviews in Food Science and Nutrition, vol. 57, pp. 2924-2933, 2017.

[19] A. A. Latif, S. Mushtaq, S. Fazal, M. Mansha, and A. J. B. Yaqub, "Seroprevalence of Toxoplasma gondii among 
pregnant women in Lahore, Pakistan,” Biologia, vol. 63, no. 2, pp. 141-146, 2017.

[20] Z. Tasawar, F. Aziz, M. H. Lashari et al., "Seroprevalence of Human toxoplasmosis in southern Punjab, Pakistan," Pakistan Journal of Life and Social Sciences, vol. 10, pp. 48-52, 2012.

[21] A. Majid, S. Khan, A. H. Jan et al., "Chronic toxoplasmosis and possible risk factors associated with pregnant women in Khyber Pakhtunkhwa," Biotechnology \& Biotechnological Equipment, vol. 30, pp. 733-736, 2016.

[22] J. P. Dubey, “Toxoplasmosis in sheep-the last 20 years," Veterinary Parasitology, vol. 163, pp. 1-14, 2009.

[23] M. Sharif, S. Sarvi, A. Shokri et al., "Toxoplasma gondii infection among sheep and goats in Iran: a systematic review and meta-analysis," Parasitology Research, vol. 114, pp. 1-16, 2015.

[24] A. P. Lopes, J. P. Dubey, F. Neto et al., "Seroprevalence of Toxoplasma gondii infection in cattle, sheep, goats and pigs from the North of Portugal for human consumption," Veterinary Parasitology, vol. 193, pp. 266-269, 2013.

[25] A. Kamal, J. U. Din, A. Kamil et al., "Seroprevalence of Toxoplasma gondii in sheep and buffalo of District Charsadda, Khyber Pakhtunkhwa, Pakistan," International Journal of Biosciences, vol. 14, pp. 497-502, 2019.

[26] M. Shah, M. Zahid, P. Asmat, A. Alam, and A. Sthanadar, "Seroprevalence of Toxoplasma gondii in goats and sheep of district Mardan, Pakistan," International Journal of Biosciences, vol. 7, pp. 90-97, 2013.

[27] S. Niaz, R. Ullah, B. Said et al., "Evaluation of sero-prevalence of toxoplasma gondii infection in sheep using different immunodiagnostic methods," Indian Journal of Animal Research, 2016.

[28] F. Said, F. Jalal, M. Imtiaz, M. A. Khan, and S. Hussain, "General distribution of different arthropods species associated with sunflower in Khyber Pakhtunkhwa:(A survey of Peshawar, Mardan and Swabi District:)," Pure and Applied Biology, vol. 7, pp. 1144-1160, 2018.

[29] S. Almería and F. López-Gatius, "Bovine neosporosis: clinical and practical aspects," Research in Veterinary Science, vol. 95, pp. 303-309, 2013.

[30] L. D. J. V. C. F. A. P. Holler, "Ruminant abortion diagnostics," Veterinary Clinics of North America: Food Animal Practice, vol. 28, pp. 407-418, 2012.

[31] A. J. C. Cook, R. Holliman, R. E. Gilbert et al., "Sources of toxoplasma infection in pregnant women: European multicentre case-control studyCommentary: congenital toxoplasmosis-further thought for food," BMJ, vol. 321, no. 7254, pp. 142$147,2000$.

[32] M. Zhou, S. Cao, F. Sevinc et al., "Enzyme-linked immunosorbent assays using recombinant TgSAG2 and NcSAG1 to detect Toxoplasma gondii and Neospora caninum-specific antibodies in domestic animals in Turkey," Journal of Veterinary Medical Science, vol. 78, pp. 1877-1881, 2016.

[33] Y. M. Al-Kappany, I. E. Abbas, B. Devleesschauwer, P. Dorny, M. Jennes, and E. Cox, "Seroprevalence of anti-Toxoplasma gondii antibodies in Egyptian sheep and goats," BMC Veterinary Research, vol. 14, p. 120, 2018.

[34] L. Baril, T. Ancelle, V. R. Goulet, P. Thulliez, V. R. TirardFleury, and B. Carme, "Risk factors for Toxoplasma infection in pregnancy: a case-control study in France," Scandinavian Journal of Infectious Diseases, vol. 31, no. 3, pp. 305-309, 1999.
[35] T. Moreno, F. Martinez-Gomez, and C. Becerra, "The seroprevalence of bovine toxoplasmosis in Cordoba, Spain," Annals of Tropical Medicine and Parasitology, vol. 85, pp. 285-286, 2016.

[36] I. Klun, O. Djurković-Djaković, S. Katić-Radivojević, and A. Nikolić, "Cross-sectional survey on Toxoplasma gondii infection in cattle, sheep and pigs in Serbia: seroprevalence and risk factors," Veterinary Parasitology, vol. 135, no. 2, pp. 121-131, 2006.

[37] M. Kritsepi-Konstantinou, Serological survey for toxoplasmosis in cattle, Deltio Ellinikis Ktiniatrikis Etaireias, 1992.

[38] L. Rinaldi and A. Scala, "Toxoplasmosis in livestock in Italy: an epidemiological update," Parassitologia, vol. 50, no. 1-2, pp. 59-61, 2008.

[39] T. R. Santos, A. J. Costa, G. H. Toniollo et al., "Prevalence of anti-Toxoplasma gondii antibodies in dairy cattle, dogs, and humans from the Jauru micro-region, Mato Grosso state, Brazil," Veterinary Parasitology, vol. 161, pp. 324-326, 2009.

[40] S. O. Nieto and R. D. Melendez, "Seroprevalence of Toxoplasma gondii in goats from arid zones of Venezuela," The Journal of Parasitology, vol. 84, no. 1, pp. 190-191, 1998.

[41] N. Yang, H. Li, J. He, M. Mu, and S. Yang, "Seroprevalence of Toxoplasma gondii infection in domestic sheep in Liaoning Province, northeastern China," The Journal of Parasitology, vol. 99, no. 1, pp. 174-175, 2013.

[42] S. P. Sharma, E. K. Baipoledi, J. F. C. Nyange, and L. Tlagae, Isolation of Toxoplasma Gondii from Goats with a History of Reproductive Disorders and the Prevalence of Toxoplasma and Chlamydial Antibodies, 2003.

[43] E. Gilot-Fromont, D. Aubert, S. Belkilani et al., "Landscape, herd management and within-herd seroprevalence of Toxoplasma gondii in beef cattle herds from Champagne-Ardenne, France," Veterinary Parasitology, vol. 161, no. 1-2, pp. 36-40, 2009.

[44] T. R. Slifko, H. V. Smith, and J. B. Rose, "Emerging parasite zoonoses associated with water and food," International Journal for Parasitology, vol. 30, no. 12-13, pp. 1379-1393, 2000.

[45] N. Arefkhah, B. Sarkari, S. Rozrokh, Z. Rezaei, and A. Moshfe, "Toxoplasmosis in nomadic communities: a seroepidemiological study in Southwestern Iran," Annali di Igiene, vol. 32, no. 1, pp. 50-55, 2020.

[46] B. Pagmadulam, P. Myagmarsuren, N. Yokoyama, B. Battsetseg, and Y. Nishikawa, "Seroepidemiological study of Toxoplama gondii in small ruminants (sheep and goat) in different provinces of Mongolia," Parasitology International, vol. 74, article 101996, 2020.

[47] W. Van der Puije, K. Bosompem, E. Canacoo, J. Wastling, and B. D. Akanmoria, "The prevalence of anti-Toxoplasma gondii antibodies in Ghanaian sheep and goats," Acta Tropica, vol. 76, pp. 21-26, 2000.

[48] N. Tzanidakis, P. Maksimov, F. J. Conraths et al., “Toxoplasma gondii in sheep and goats: Seroprevalence and potential risk factors under dairy husbandry practices," Veterinary Parasitology, vol. 190, no. 3-4, pp. 340-348, 2012.

[49] M. Ramzan, M. Akhtar, F. Muhammad et al., "Seroprevalence of Toxoplasma gondii in sheep and goats in Rahim Yar Khan (Punjab), Pakistan," Tropical Animal Health and Production, vol. 41, no. 7, pp. 1225-1229, 2009.

[50] D. E. Hill and J. P. Dubey, “Toxoplasma gondii prevalence in farm animals in the United States," International Journal for Parasitology, vol. 43, no. 43, pp. 107-113, 2013. 
[51] N. Zhang, S. Wang, D. Wang et al., "Seroprevalence of Toxoplasma gondii infection and risk factors in domestic sheep in Henan province, central China," Parasite, vol. 23, p. 53, 2016.

[52] C. Nogareda, A. Jubert, V. Kantzoura, M. Kouam, H. Feidas, and G. J. Theodoropoulos, "Geographical distribution modelling for Neospora caninum and Coxiella burnetii infections in dairy cattle farms in northeastern Spain," Epidemiology and Infection, vol. 141, pp. 81-90, 2013.

[53] A. Hussain and M. Zahid, Seroprevalence of Toxoplasma gondii infection in domestic animals of district Charsadda, Khyber Pakhtunkhwa, Pakistan.

[54] I. A. Faisal, A. U. Khan, M. Waqar et al., "Distribution of Toxoplasma gondii in the pregnant women of district Swabi Khyber Pakhtunkhwa Pakistan," World Applied Sciences Journal, vol. 29, pp. 77-79, 2014.

[55] M. S. Ahmad, A. Maqbool, M. Mahmood-ul-Hassan, M. Mushtaq-ul-Hassan, and A. A. Anjum, "Prevalence of Toxoplasma gondii antibodies in human beings and commensal rodents trapped from Lahore, Pakistan," Journal of Animal and Plant Science, vol. 22, pp. 51-53, 2012.

[56] A. Tenter, A. Heckeroth, and L. M. Weiss, "Erratum-Toxoplasma gondii: from animals to humans," International Journal for Parasitology, vol. 31, pp. 217-220, 2001.

[57] M. A. Hussain, V. Stitt, E. A. Szabo, and B. Nelan, "Toxoplasma gondii in the food supply," Pathogens, vol. 6, no. 2, p. 21, 2017.

[58] S. Boughattas and A. Bouratbine, "Prevalence of food-borne Toxoplasma gondii in free-ranging chickens sold in Tunis, Tunisia," Journal of food quality and hazards control, vol. 1, pp. 89-92, 2014. 